\begin{tabular}{lcc}
\hline \multicolumn{3}{c}{ ANNALES } \\
UNIVERSITATIS MARIAE CURIE-SKŁODOWSKA & \\
& LUBLIN - POLONIA & \\
VOL. LXXIII, 1 & SECTIO AA & 2018 \\
\hline
\end{tabular}

\title{
Application of screen-printed sensors for the determination of painkillers
}

\author{
Agnieszka Sasal* and Katarzyna Tyszczuk-Rotko \\ Department of Analytical Chemistry and Instrumental Analysis, \\ Faculty of Chemistry, Maria Curie-Skłodowska University \\ Maria Curie-Skłodowska Sq. 3, 20-031 Lublin \\ *email: agnieszka.szwagierek@poczta.umcs.lublin.pl
}

\begin{abstract}
This paper addresses the problem of the intensive development of the pharmaceutical industry and its consequences for the natural environment. The characteristics of the most commonly consumed pharmaceutical preparations and the ways of these substances penetrating into water ecosystems are presented. Attention was paid to the need to monitor environmental contamination and to search for new methods that would enable routine quality control of natural water samples. The application of modern, miniature screenprinted sensors for the determination of trace concentrations of selected active substances of pharmaceutical preparations are presented.
\end{abstract}

\section{INTRODUCTION}

Pharmaceutical preparations constitute a very wide group of biologically active compounds which when introduced into the living organism have a therapeutic effect. The substances used in medicine are more or less complicated in terms of chemical composition or structure. The progress of chemistry and biological sciences has led to an avalanche increase in the number of 
pharmaceutical preparations. Most of the currently used drugs are of synthetic origin, however, there are also medicines of plant origin (e.g. tincture from valerian), preparations produced and isolated from animal tissues, produced by genetic engineering methods (e.g. human insulin) and medicines derived from natural mineral resources (e.g. bentonite).

The huge amount of drugs currently used introduces the need for their classification. Drugs were divided into groups most often according to the criterion of their pharmacological action and their use in specific disease entities. Drugs were ordered in the anatomicaltherapeutic-chemical classification (ATC), which orders them because of the target site of action, therapeutic function, pharmacological characteristics and belonging to a specific chemical group. One of the first groups on the list of primary drugs of the World Health Organization are analgesics, these are chemical substances that cause analgesia, i.e. the elimination of the sensation of pain. Among them, the basic division of opioid and non-opioid drugs was distinguished. Opioids lead to the closure of the calcium channel and the opening of the potassium channel in the opioid receptors, which leads to a reduction in the nerve conduction in the posterior corners of the spinal cord. Opioids were divided into weak opioids, e.g. codeine and strong opioids, e.g. morphine. Non-opiate drugs are primarily nonsteroidal anti-inflammatory drugs (NSAIDs), which are a wide, heterogeneous group of anti-inflammatory, analgesic and antipyretic drugs. Their action is based on the inhibition of prostaglandin cyclooxygenase (COX), which is at the same time the basis of their qualification.

There were three groups among non-steroidal anti-inflammatory drugs: NSAIDs of the 1st generation, e.g. acetylsalicylic acid, diclofenac, ibuprofen, 2nd generation NSAIDs, e.g. meloxicam and NSAIDs of the 3rd generation, e.g. celecoxib. In addition to drugs from the group of non-steroidal anti-inflammatory drugs, there is also paracetamol, which is one of the most popular painkillers in the world. Paracetamol is a drug that works mainly centrally, while other NSAIDs act mainly in the place of pain. The mechanism of action of paracetamol has not been clearly explained by scientists. Pharmaceutical preparations from the NSAID group constitute the largest number of sold and consumed medicines on the market. The Polish pharmaceuticals market is ranked 6th in Europe, according to KPMG and PMR. Nearly 34\% of the market is OTC preparations, 
available without a prescription, of which $26 \%$ are analgesics [1]. The increase in the consumption of pharmaceutical preparations causes a direct increase in pollution of the natural environment, including aquatic ecosystems, medicinal substances and products of their decomposition. Traces of pharmaceuticals were detected in samples taken from treated wastewater, surface and groundwater. It was found that the most commonly occurring drugs in the environment are drugs from the group of non-steroidal anti-inflammatory drugs, paracetamol, antibiotics, drugs regulating lipid metabolism, hormonal agents, $\beta$-blockers and psychotropic drugs [2]. Pharmaceutical preparations penetrate the environment primarily as a result of their production in pharmaceutical industry production plants, but also as a result of improper disposal of medical waste in hospitals and health centres. A significant amount of pharmacologically active substances is produced for veterinary and animal husbandry purposes. In addition, virtually every household is a source of pollution. Ingested pharmaceutical preparations undergo biotransformation in the body and are excreted unchanged from the body or as metabolites of the original substances. All these substances go to the sewage treatment plant. Traditional methods of wastewater treatment are insufficient to eliminate all pharmaceutical preparations from water, which makes municipal sewage treatment plants a serious source of drugs and their metabolites entering the environment. In addition, expired and unused pharmaceutical preparations are often discarded without proper disposal, ending up in a landfill where they can leak into the environment.

A similar situation occurs when using drugs in animal husbandry and agriculture. The content of pharmaceuticals in aquatic ecosystems shows great variability, their occurrence in the environment depends on hydrological, climatic and demographic conditions as well as land use [3]. Higher concentration of pharmaceutical preparations in sewage waters of large cities and seasonal variability was observed [4]. The increase in the consumption of pharmaceutical preparations is mainly in the autumn and winter period of increased incidence of influenza and cold. This results in a direct increase in the pollution of ground and surface water. The low temperature of water hinders the process of biodegradation, and a short day limits the process of photolysis, which additionally favours the accumulation of organic compounds by plants and animals, causing them a number of diseases. The 
presence of pharmaceutical preparations in drinking water is also a serious threat to people, because it disturbs the balance in the body and intensifies the problem of drug resistance [5]. The presence of pharmaceutical preparations in the environment is a serious problem, therefore their level should be constantly monitored.

The literature contains many works devoted to the methods of determining impurities in water samples, however, these works mainly focus on laboratory methods, often characterized by high cost of the apparatus and the measurement itself. These are usually chromatographic and spectrophotometric methods. In the case of these methods, there are many stages leading from sampling the source to its final analysis, including sample transport to the laboratory, storage, maintenance, enrichment or isolation of analytes, proper storage of extracts, preparation of a sample for measurement and time-consuming analysis [1]. However, for the assessment of water quality, field analysis may also be applied, including determination of selected physicochemical or chemical properties of water. It allows for continuous and quick control, both qualitative and quantitative, carried out directly in the field. This allows early detection of emergency water contamination. Field analysis may also be an indicator, approximate or control analysis and a preliminary analysis for later more detailed studies. Portable analysers allow for monitoring the quality of surface water, underground water, sea water, industrial sewage and drinking water. The operation of portable analysers is based on various measurement methods. Currently, more and more attention is devoted to electrochemical methods, due to the possibility of miniaturization of the apparatus and the construction of new ones, characterized by good repeatability, selectivity and sensitivity of electrochemical, miniature sensors. Examples of this type of electrodes are composite, screenprinted three-electrode systems.

The screen-printing technology was first used for the production of electronic systems used to determine blood glucose in the late eighties of the last century. Currently, thanks to the use of this technology, miniature screen-printed sensors are obtained, which are characterized by low cost of production and high repeatability. The production of this type of electrodes consists in applying the appropriate ink to the prepared ceramic or plastic substrate. The advantage of this approach is the ability to modify the composition of the applied ink, which affects the selectivity and sensitivity of the 
designed sensor. The commercially available screen-printing surfaces can be modified using metal nanoparticles and carbon materials, e.g. graphene, nanotubes and nanofibers, as well as using polymers, enzymes or complexing compounds. This shortens the analysis time, because the electrode surface does not require additional preparation before the measurement, as is the case with conventional electrodes. It is also possible to modify the surface of finished electrodes by applying a polymer film, enzyme or metal modification. Screenprinting technology ensures precise control of the dimensions of screen-printed electrodes, excellent homogeneity, high reproducibility and potential for mass production.

Thanks to the use of screen-printing technology in the serial production of disposable, inexpensive electrodes for electrochemical determination of a wide range of substances, a continuous increase in interest and development of sensor production is observed. The screen-printed electrodes are small in size and allow analysis of small volumes of organic compounds and inorganic metal ions at low concentrations.

This article reviews the methods for the determination of selected active substances of popular pharmaceutical preparations using screen-printed electrodes. It was decided to describe three active substances of pharmaceutical preparations: acetylsalicylic acid, ibuprofen and paracetamol, as these compounds are most often consumed by the society and occur in the largest amounts in the aquatic environment.

\section{ACETYLSALICYLIC ACID}

Acetylsalicylic acid (2-Acetoxybenzoic acid), commonly referred to as Aspirin, was the first synthetic drug. The synthesis of aspirin is considered the beginning of the pharmaceutical industry. It is an organic chemical compound, an acetyl derivative of salicylic acid, whose structural formula is shown in Figure 1(a).

Acetylsalicylic acid is a popular compound with analgesic, antipyretic and anti-inflammatory effects. With long-term use, it has anticoagulant activity. WHO recognized acetylsalicylic acid as one of the best agents for use on the first level analgesic ladder, for the treatment of mild to moderate pain associated with cancer. 
Another important feature of acetylsalicylic acid used in medicine is the ability to inhibit cyclooxygenase in the platelets in which it is responsible for the production of thromboxane. In this way, aspirin inhibits the ability of platelets to aggregate and form clots.

In an aqueous solution, the acetic acid residue is detached from acetylsalicylic acid and then salicylic acid is oxidized. The suggested mechanism of acetylsalicylic acid oxidation is shown in Fig. 1. The oxidation peak of salicylic acid was observed at a potential about $0.7 \mathrm{~V}$. The determination of acetylsalicylic acid was carried out in a solution of phosphate buffer of $\mathrm{pH}$ equal to $4.0[7,8]$.

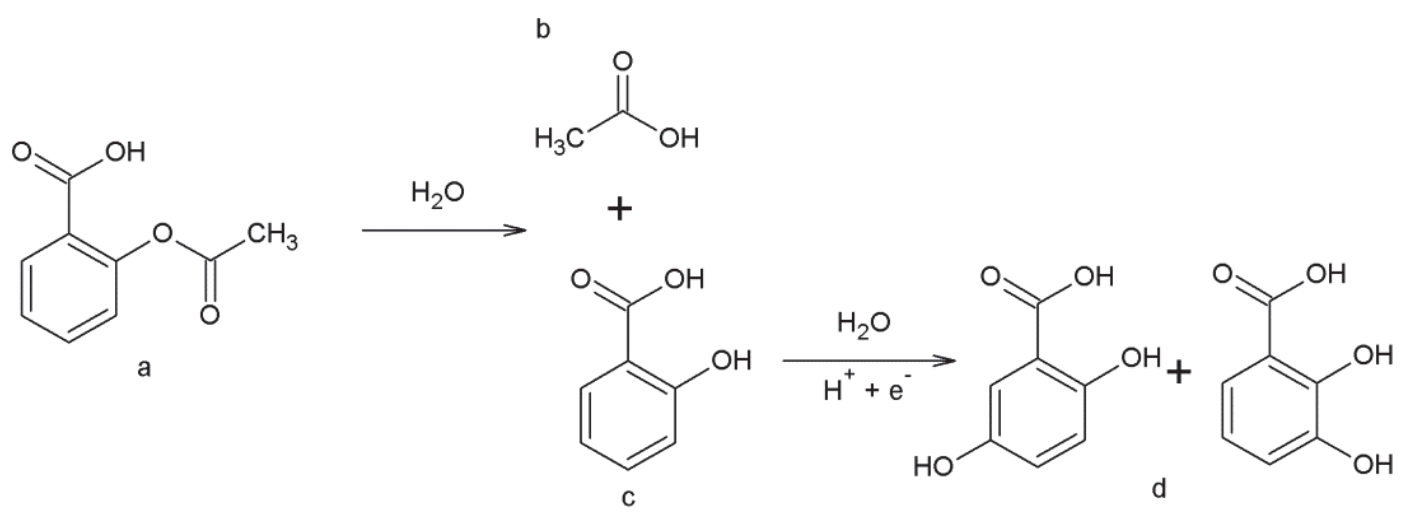

Fig. 1. Suggested mechanism of acetylsalicylic acid oxidation. Structural formula of (a) acetylsalicylic acid, (b) acetic acid, (c) salicylic acid, (d) oxidation products of salicylic acid.

Two works describing the determination of acetylsalicylic acid on screen-printed electrodes have been found in the literature. The first paper proposed by Senee Kruanetr et al. [7] describes the procedure for the determination of acetylsalicylic acid on a graphene modified screen-printed electrode using cyclic voltammetry and has found application in the determination of substances in biological matrixes such as human oral fluid. In the second paper, Chunzhi Zhao and Jihong Lin [8] developed a method for the determination of acetylsalicylic acid on Nafion and electrochemically reduced graphene oxide modified screen-printed electrode.

This method has also found application for the determination of acetylsalicylic acid in human slime samples. Both works were compared in Table 1. 
Table 1. Electrochemical methods for determining acetylsalicylic acid on screen-printed electrodes.

\begin{tabular}{|c|c|c|c|c|c|}
\hline Electrode & Method & $\begin{array}{c}\text { Linear range } \\
{\left[\mathrm{mol} / \mathrm{dm}^{3}\right]}\end{array}$ & $\begin{array}{c}\mathrm{LOD} \\
{\left[\mathrm{mol} / \mathrm{dm}^{3}\right]}\end{array}$ & Application & Ref. \\
\hline SPGrE & $\mathrm{CV}$ & $1 \cdot 10^{-7}-1 \cdot 10^{-4}$ & $5 \cdot 10^{-9}$ & $\begin{array}{l}\text { Human oral } \\
\text { fluid }\end{array}$ & [7] \\
\hline $\begin{array}{c}\text { Nafion/ } \\
\text { Er-GO/SPE }\end{array}$ & $\mathrm{CV}$ & $1 \cdot 10^{-7}-1 \cdot 10^{-4}$ & $5 \cdot 10^{-8}$ & $\begin{array}{l}\text { Human oral } \\
\text { fluid }\end{array}$ & [8] \\
\hline \multicolumn{6}{|c|}{$\begin{array}{l}\text { SPGrE - graphene modified screen-printed electrode, } \\
\text { Nafion/Er-GO/SPE - electrochemically reduced Graphene oxide/Nafion/ screen- } \\
\text { printed electrode } \\
\text { CV - cyclic voltammetry } \\
\text { LOD - limit of detection }\end{array}$} \\
\hline
\end{tabular}

\section{IBUPROFEN}

Ibuprofen ((RS)-2-(4-(2-Methylpropyl)phenyl)propanoic acid) is an organic chemical compound whose structural formula is shown in Fig. 2a, a propionic acid derivative belonging to the group of nonsteroidal anti-inflammatory drugs, has anti-inflammatory, analgesic and antipyretic effects. In addition, ibuprofen reduces swelling, improves joint mobility, removes numbness in the joints, inhibits platelet aggregation and reduces blood clotting.<smiles></smiles>

Fig. 2. Suggested mechanism of ibuprofen oxidation. Structural formula for (a) ibuprofen, (b) oxidation product of ibuprofen.

Suggested, simplified mechanism of ibuprofen oxidation is shown in Fig. 2. Accumulation of ibuprofen on the electrode surface is controlled by diffusion. The peak of ibuprofen oxidation was 
observed at a potential of $1.1 \mathrm{~V}$. The determination of ibuprofen was carried out in a solution of acetate buffer of $\mathrm{pH}$ in the range of 4.5-4.7 [9-11].

To the best of our knowledge, there are only two papers in the literature describing the determination of ibuprofen on screenprinted electrodes. The method proposed by Sidra Amin et al. [10] is based on the determination of ibuprofen on a screen-printed graphite electrode using square wave voltammetry. This method has been used in the determination of ibuprofen in sewage and river water samples. The second work proposed by Irina Mirela Apetrez et al. [11] describes a method for the determination of ibuprofen on a screen-printed carbon electrode modified with carbon nanofibers by means of differential-pulse voltammetry and found application in the determination of ibuprofen in pharmaceutical preparations. The results described by the Authors in the above works were compared in Table 2.

Table 2. Electrochemical methods for determination of ibuprofen on screen-printed electrodes.

\begin{tabular}{|c|c|c|c|c|c|}
\hline Electrode & Method & $\begin{array}{l}\text { Linear range } \\
{\left[\mathrm{mol} / \mathrm{dm}^{3}\right]}\end{array}$ & $\begin{array}{c}\mathrm{LOD} \\
{\left[\mathrm{mol} / \mathrm{dm}^{3}\right]}\end{array}$ & Application & Ref. \\
\hline SPGE & SWV & $9.7 \cdot 10^{-6}-4.8 \cdot 10^{-5}$ & $4.8 \cdot 10^{-7}$ & $\begin{array}{l}\text { Waste water, } \\
\text { river water }\end{array}$ & [10] \\
\hline $\begin{array}{l}\text { CNF/ } \\
\text { SPCE }\end{array}$ & DPV & $8.0 \cdot 10^{-7}-3.0 \cdot 10^{-5}$ & $3.5 \cdot 10^{-7}$ & $\begin{array}{l}\text { Pharmaceutica } \\
\text { l formulations }\end{array}$ & [11] \\
\hline \multicolumn{6}{|c|}{$\begin{array}{l}\text { SPGE - screen-printed graphite electrode } \\
\text { CNF/SPCE - screen-printed electrode modified with carbon nanofibers } \\
\text { SWV - square wave voltammetry } \\
\text { DPV - differential pulse voltammetry } \\
\text { LOD - limit of detection }\end{array}$} \\
\hline
\end{tabular}

\section{PARACETAMOL}

Paracetamol, otherwise known as acetaminophen (N-(4-hydroxyphenyl)ethanamide) is an organic chemical compound, a hydroxyl derivative of acetanilide, and the structural formula is 
shown in Fig. 3a. Paracetamol, unlike the previously mentioned examples of drugs from the group NLZP, does not show antiinflammatory properties and does not prevent blood from clotting, while like other drugs it has analgesic and antipyretic properties. The use of paracetamol is recommended for: fever, cold, flu, headache, toothache, menstrual pain, muscle pain, post-operative pain and osteoarthritis. It can be used alone or in combination with NSAIDs and opioid analgesics in case of severe pain. In addition, paracetamol is characterized by a low risk of side effects and does not damage the gastric mucosa.

The suggested mechanism for paracetamol oxidation is shown in Figure 3. The oxidation peak of paracetamol was observed at a potential of $0.3 \mathrm{~V}$ or $0.6 \mathrm{~V}$. The determination of paracetamol was carried out in the Britton-Robinson buffer solution of $\mathrm{pH}$ equal to 2.0 and 6.0, phosphate buffer solution of $\mathrm{pH}$ equal to 7.4 or carbonate buffer solution of $\mathrm{pH} 9.0$ [12-20].
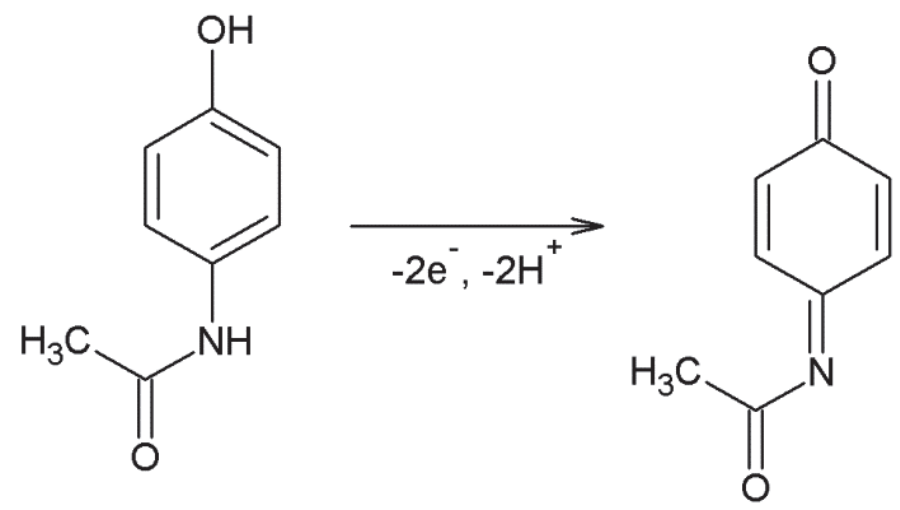

Fig. 3. Suggested mechanism for paracetamol oxidation. Structural formula of (a) paracetamol, (b) oxidation product of paracetamol.

Several works on the determination of paracetamol on screenprinted electrodes have been found in the literature. The method proposed by Shashank Sharma et al. [12] allows the determination of paracetamol on unmodified screen-printed carbon electrode by means differential pulse voltammetry in pharmaceutical preparations. Carlos Fernandez et al. [13] developed a method for the determination of paracetamol on unmodified screen-printed graphene electrode using cyclic voltammetry.

The proposed method allowed the determination of paracetamol in biological samples such as human oral fluid. The 
Thalita Rocha Saciloto team developed two methods for the determination of paracetamol on the graphite and polyurethane screen-printed composite electrode in pharmaceutical formulations.

The first work uses cyclic voltammetry as a signal recording technique [14], the second work describes the method of determining paracetamol in the presence of caffeine by means of differential pulse voltammetry [15]. Another example of the use of carbon nanomaterials as a modifier of screen-printed electrodes are works based on carbon nanotubes. Pablo Fanjul-Bolado et al. [16] have developed a method for the determination of paracetamol using carbon nanotube modified screen-printed carbon electrode. The research involved the cyclic voltammetry technique and the presented method was used to determine paracetamol in pharmaceutical preparations.

The team Jessica Stefano [17] developed a method for the simultaneous determination of paracetamol and naproxen on multiwalled carbon nanotube modified screen-printed electrode. They used the flow-injection analysis with multiple-pulse amperometric method for their research and used it to determine both substances in pharmaceutical preparations. Michaela Tertis and co-workers [18] developed a method for the determination of paracetamol on a horseradish peroxidase immobilized in single-walled carbon nanotubes-polypyrrole nanocomposite film at the surface of the screen-printed electrode. The presented method is based on the technique of differential pulse voltammetry and allows determination of paracetamol in pharmaceutical preparations. The next immunosensor developed by Oana Hosu and co-workers [19] uses a screenprinted electrode with magnetic beads modified with protein G. This method uses differential pulse voltammetry and allows the determination of paracetamol in pharmaceutical preparations.

The last work describing the determination of paracetamol was presented by the team of Bahaa Mahmoud [20]. The work uses a screen-printed graphite electrode modified with bismuth oxide for the simultaneous determination of paracetamol and isoniazid in human serum and pharmaceutical preparations using the differential pulse voltam-metry technique. The obtained results for the abovementioned methods are presented in Table 3. 
Table 3. Electrochemical methods for determination of paracetamol on screen-printed electrodes.

\begin{tabular}{|c|c|c|c|c|c|}
\hline Electrode & Method & $\begin{array}{c}\text { Linear range } \\
{\left[\mathrm{mol}^{2} \mathrm{dm}^{3}\right]}\end{array}$ & $\begin{array}{c}\text { LOD } \\
{\left[\mathrm{mol}^{\prime} / \mathrm{dm}^{3}\right]}\end{array}$ & Application & Ref. \\
\hline SPCE & DPV & $3.3 \cdot 10^{-8}-2.0 \cdot 10^{-7}$ & $6.6 \cdot 10^{-10}$ & $\begin{array}{c}\text { Pharmaceutical } \\
\text { formulations }\end{array}$ & [12] \\
\hline SPGrE & $\mathrm{CV}$ & $1.0 \cdot 10^{-7}-5.0 \cdot 10^{-5}$ & $2.0 \cdot 10^{-8}$ & Human oral fluid & [13] \\
\hline EIGPU & CV & $1.0 \cdot 10^{-6}-1.0 \cdot 10^{-4}$ & $8.2 \cdot 10^{-7}$ & $\begin{array}{c}\text { Pharmaceutical } \\
\text { formulations }\end{array}$ & [14] \\
\hline EIGPU & DPV & $1.0 \cdot 10^{-6}-4.0 \cdot 10^{-5}$ & $8.4 \cdot 10^{-7}$ & $\begin{array}{l}\text { Pharmaceutical } \\
\text { formulations }\end{array}$ & [15] \\
\hline $\begin{array}{l}\text { CNT/ } \\
\text { SPCE }\end{array}$ & $\mathrm{CV}$ & $2.5 \cdot 10^{-6}-1.0 \cdot 10^{-3}$ & $1.0 \cdot 10^{-7}$ & $\begin{array}{l}\text { Pharmaceutical } \\
\text { formulations }\end{array}$ & [16] \\
\hline $\begin{array}{c}\text { MWCNT/ } \\
\text { SPE }\end{array}$ & $\begin{array}{l}\text { FIA- } \\
\text { MPA }\end{array}$ & $1.0 \cdot 10^{-5}-8.0 \cdot 10^{-4}$ & $4.0 \cdot 10^{-7}$ & $\begin{array}{c}\text { Pharmaceutical } \\
\text { formulations }\end{array}$ & [17] \\
\hline $\begin{array}{c}\text { HRP/ } \\
\text { SWCNT/ } \\
\text { Ppy/SPE }\end{array}$ & DPV & $2.4 \cdot 10^{-5}-1.2 \cdot 10^{-4}$ & $8.1 \cdot 10^{-6}$ & $\begin{array}{l}\text { Pharmaceutical } \\
\text { formulations }\end{array}$ & [18] \\
\hline $\begin{array}{c}\text { MBs / } \\
\text { Protein-G/ } \\
\text { SPE }\end{array}$ & DPV & $1.0 \cdot 10^{-5}-7.5 \cdot 10^{-4}$ & $1.8 \cdot 10^{-6}$ & $\begin{array}{c}\text { Pharmaceutical } \\
\text { formulations }\end{array}$ & [19] \\
\hline $\mathrm{BiO} / \mathrm{SPE}$ & DPV & $5.0 \cdot 10^{-6}-9.7 \cdot 10^{-5}$ & $1.9 \cdot 10^{-6}$ & $\begin{array}{l}\text { Human serum, } \\
\text { pharmaceutical } \\
\text { formulations }\end{array}$ & [20] \\
\hline
\end{tabular}

SPCE - screen-printed carbon electrode

SPGrE - screen-printed graphene electrode

EIGPU - graphite and polyurethane screen-printed composite electrode

CNT/SPCE - carbon nanotube modified screen-printed carbon electrode

MWCNT/SPE - multi-walled carbon nanotube modified screen-printed electrode

HRP/SWCNT/Ppy/SPE - Horseradish peroxidase immobilized in single-walled carbon nanotubes-polypyrrole nanocomposite film at the screen-printed electrode MBs/Protein-G/SPE - Screen-printed electrode with magnetic beads modified with protein $\mathrm{G}$

BiO/SPE - Bismuth oxide modified screen-printed electrode

DPV - differential pulse voltammetry

CV - cyclic voltammetry

FIA-MPA - flow-injection analysis with multiple-pulse amperometric

LOD - limit of detection 


\section{CONCLUSIONS}

The intensive development of the pharmaceutical industry and the continuous increase of sales and consumption of medicines by people, increases the environmental pollution with pharmaceutical preparations. Residues of these substances get through different routes to aquatic ecosystems and are accumulated in them, thus affecting negatively on plants and animals, but above all on human health. This causes the search for new apparatus and methodological solutions that enable the determination of ever lower concentrations of many pharmaceutical preparations in samples with a complex matrix composition. For this purpose, modern screen-printed sensors can be used, whose miniature size allows field analyses to be carried out. Such analyses allow for continuous and fast control analysis of water quality as well as for limiting research time and costs.

\section{REFERENCES}

[1] A. Szymonik, J. Lach, Inżynieria i Ochrona Środowiska, 15(3), 249, (2012).

[2] A. Nikolaou, S. Meric, D. Fatta, Analytical and Bioanalytical Chemistry, 387, 1225, (2007).

[3] A. B. A. Boxall, M. A. R. Rudd, B. W. Brooks et al., Environmental Health Perspectives, 120(9), 1221, (2012).

[4] Y. Yu, L. Wu, A. C. Chang, Science of the Total Environment, 442, 310, (2013).

[5] L. A. Schaider, K. M. Rodgers, R. A. Rudel, Environmental Science \& Nanotechnology, 51, 7304, (2017).

[6] O. D. Renedo, M. A. Alonso-Lomillo, M. J. Arcos Martinez, Talanta, 73, 202, (2007).

[7] S. Kruanetr, R. Prabhu, P. Pollard, C. Fernandez, Surface Engineering and Applied Electrochemistry, 51(3), 283, (2015).

[8] C. Zhao, J. Lin, International Journal of Electrochemical Science, 12, 10177 (2017).

[9] L. Svorc, I. Strezova, K. Kianickova, D.M. Stankovic, P. Otrisal, A Samphao, Journal of Electroanalytical Chemistry, 822, 144, (2018).

[10] S. Amin, M. T. Soomro, N. Memon, A. R. Solangi, Sirajuddin, T. Qureshi, A. R. Behzad, Environmental Nanotechnology, Monitoring \& Management, 1-2, 8, (2014). 
[11] I. M. Apetrei, A. A. Bejinaru, M. Boev, C. Apetrei, O. D. Buzia, Farmacia, 65, 5, (2017).

[12] S. Sharma, S. K. Khanna, J. Singh, S. P. Satsangee, Oriental Journal of Chemistry, 31, 201, (2015).

[13] C. Fernandez, Z. Heger, R. Kizek, T. Ramakrishnappa, A. Boruń, N. H. Faisal, International Journal of Electrochemical Science, 10, 7440, (2015).

[14] T. R. Saciloto, P. Cervini, E. T. G. Cavalheiro, Analytical Letters, 46, 312, (2013).

[15] T. R. Saciloto, P. Cervini, E. T. G. Cavalheiro, Journal of the Brazilian Chemical Society, 24(9), 1461 (2013).

[16] P. Fanjul-Bolado, P. J. Lamas-Ardisana, D. Hernandez-Santos, A. CostaGarcia, Analytica Chimica Acta, 638, 133 (2009).

[17] J. S. Stefano, R. H. O. Montes, E. M. Richter, R. A. A. Munoz, Journal of the Brazilian Chemical Society, 25(3), 484, (2014).

[18] M. Tertis, A. Florea, R. Sandulescu, C. Cristea, Sensors, 13, 4841, (2013).

[19] O. Hosu, M. Tertis, R. Sandulescu, C. Cristea, Farmacia, 63, 1, (2015).

[20] B. G. Mahmoud, M. Khairy, F. A. Rashwan, C. E. Banks, Analytical Chemistry 89, 2170, (2017). 
